\title{
OS BEBÊS E A CRECHE: REFLEXÕES SOBRE O DIREITO À QUALIDADE DAS INTERAÇÕES
}

\author{
Edilane Oliveira da Silva ${ }^{\mathrm{i}}$ \\ Lívia Larissa de Lima Lage ii \\ Michelle Dantas Ferreira ${ }^{\text {iii }}$
}

\begin{abstract}
RESUMO: O artigo discute o conceito de bebê enquanto sujeito de ação e direitos, dialogando com a concepção de creche como um espaço no qual a Educação se materializa nas práticas sociais, apostando no fortalecimento dos vínculos em prol dos direitos infantis. Observando situações concretas de interação registradas em uma Creche Municipal do Rio de Janeiro, analisamos que a construção de um olhar para os bebês, enquanto sujeitos, requer uma presença atenta e sensível do educador, o que envolve as condições de trabalho e reflete na qualidade das interações intersubjetivas. Apostamos na estesia das relações para a possibilidade de um novo olhar e na construção de um trabalho dedicado, sutil que considere as potencialidades dos bebês no encaminhamento das propostas educativas que os envolvam.
\end{abstract}

Palavras-chave: Bebês; Creche; Educação Estética; Interações.

\begin{abstract}
The article discusses the concept of infants as a subject of action and rights, dialoguing with the concept of day care as a space in which Education materializes in social practices, looking forward on the strengthening of bonds in favor of children's rights. Concrete situations of interaction were registered in a Rio de Janeiro's Municipal Day Care Center and we analyze that the look construction at infants as subjects requires an attentive and sensitive presence of the educator, which involves labor conditions and reflects on the quality of intersubjective interactions. We bet on the esthesis of relationships in order to the possibility of a new viewpoint and to the dedicated and subtle work construction, that taking into account the potential of babies in guiding educational proposals that involve them.
\end{abstract}

Keywords: Child; Child day care centers; Aesthetic Education; Interactions.

\section{OS BEBÊS, A CRECHE E AS INTERAÇÕES}

Pensar os bebês como sujeitos de direitos, dotados de competências que se (re)constroem em relação dialógica com o mundo e com os que estão à sua volta é atitude de resistência. Isso porque numa sociedade que parece pautar-se constantemente no que está por vir, em que o presente é vivido visando conquistas futuras, a Educação assume a perspectiva do "vir a ser", insistindo em olhar a criança - sobretudo os bebês - como alguém que ainda não é. Assim,

2020 Bargas; Ayoub; Assaritti, Scarazzatto, Assis. Este é um artigo de acesso aberto distribuído sob os termos da Licença Creative Commons Atribuição Não ComercialCompartilha Igual (CC BY-NC-4.0), que permite uso, distribuição e reprodução para fins não comerciais, com a citação dos autores e da fonte original e sob a mesma licença 
enxergá-los com atenção e dedicar respeito aos acontecimentos que se passam no momento atual de sua existência, a fim de apoiar suas conquistas e fazer ecoar suas competências, soa utópico.

Quais acontecimentos seriam esses? O que fazem os bebês? Segundo Myrtha Chokler (2010, p. 11), "é preciso delinear outra imagem das crianças como sujeitos de ação e não somente de reação". A construção dessa nova imagem é o que permitiria apreciarmos concretamente a competência das iniciativas e a potência do encantamento com o qual estes sujeitos de ação interagem com o mundo. Encantamento e movimento são meios pelos quais descobrem a si mesmos e também ao que está no seu entorno. Trata-se de notar o desenvolvimento da criança como um duplo deslocamento: para fora e para dentro, no qual sua inteireza está permanentemente implicada e as aprendizagens vão se constituindo de forma dinâmica, com grande iniciativa da criança.

Diante disso, esse trabalho se dispõe a pensar as relações estabelecidas com e entre os bebês, a partir do olhar e da escuta de uma de nós, professora-pesquisadora, que atua profissionalmente no berçário de uma creche pública situada na zona sul da cidade do Rio de Janeiro. Relações essas apreciadas ao observar os bebês e os adultos que lidam diretamente com eles nos diferentes espaços por onde circulam (sala, solário, refeitório, parque) nessa instituição; atentando para a vitalidade das ações e reações presentes nos encontros intersubjetivos - dos bebês entre si e com os adultos - e para as manifestações das especificidades subjetivas de cada um deles.

Nosso interesse se volta a compreender cada bebê singularmente, de maneira concreta e contextualizada, atentas a seu enredo familiar, seus ritmos, interesses e desafios individuais. Simultaneamente, queremos compreendê-los também enquanto sujeitos que se desenvolvem em uma coletividade, na interação com o outro e com as materialidades e demais elementos do ambiente da Creche em questão.

Apontamos a observação e o registro (fotográfico e em diário de campo), a escuta e o diálogo como meios de trazer a figura da professora ${ }^{4}$ e seus saberes a essa elaboração, defendendo com isso, uma qualidade de estesia nas interações, que ressalta a importância do vínculo, do toque, das percepções sensíveis no trabalho com os bebês, pois essa é uma pesquisa que nasce do dia a dia compartilhado entre professoras e bebês na Creche, e contempla os desafios, sabores e saberes que as interações entre esses diferentes atores provocam.

Revista Interinstitucional Artes de Educar. Rio de Janeiro, V. 6, N.2- pág. 627-652 maio-agosto de 2020: "Bebês e crianças: cultura, linguagem e políticas"

DOI: 10.12957/riae.2020.46228 
Nos debruçamos conjuntamente sobre tais observações, registradas em fotografias e diário de campo, que nos incitaram a desenvolver uma mirada atenta e empática para os bebês e suas competências atuais, permitindo recolher vestígios sobre o percurso de desenvolvimento de cada um deles e atentar para suas expressões, movimentos, gestos, diálogos; descortinando a relevância e a intensidade das descobertas realizadas a partir da iniciativa dos bebês, bem como notando a força dos olhares e vínculos que dão suporte para que cada um usufrua de suas potencialidades nas interações com o outro. Acreditamos que tudo isso contribui para a construção gradativa da identidade de cada sujeito, para o desabrochar de suas "personalidades competentes" (SZANTO-FEDER; TARDOS, 2011).

Supomos, contudo, que para alcançar uma observação atenta e não naturalizada sobre os bebês, a partir da perspectiva anunciada anteriormente, é necessária determinada disponibilidade sensível do educador. Assim, apostamos e defendemos a ideia de uma Educação Estética, cujos efeitos impactam a qualidade da formação dos sujeitos - desde a creche ao ensino superior -, justamente por implicá-los em sua globalidade - aspectos emocionais, cognitivos, corporais e afetivos.

Isso traz à cena a necessidade de refletirmos também sobre a formação docente. Pautando-nos na ideia de que "há forte homologia entre as experiências dos professores e dos alunos" $"$ (DUBET, 2002 apud CANÁRIO, 2005), compreendemos que a construção de novas formas de enxergar e interagir com as crianças no âmbito da instituição educacional suscita o despertar da dimensão sensório perceptiva do próprio educador, que muitas vezes permanece adormecida e desmobilizada ao longo do percurso formativo escolar/acadêmico.

Acreditamos que uma Educação que envolva de forma intencional e privilegiada a dimensão estética do humano é provocadora de deslocamentos necessários para acordar os sentidos de seus condicionamentos e presenciar as manifestações infantis a partir de novas perspectivas. O termo "estética" vem do grego "aisthesis", "aistheton" e significa apreciação sensorial, conhecimento sensível (HERMANN, 2005). Despertar a sensopercepção é meio de desnaturalizar as concepções de criança, Educação, docência introjetadas a partir das representações sociais correntes e também das experiências escolares prévias dos sujeitos em formação, que são fortes condicionantes das práticas educativas, mas raras vezes se apresentam como objeto de reflexão no processo formativo (CANÁRIO, 2006; TARDIF, 2014).

Revista Interinstitucional Artes de Educar. Rio de Janeiro, V. 6, N.2-pág. 627-652 maio-agosto de 2020: "Bebês e crianças: cultura, linguagem e políticas"

DOI: 10.12957/riae.2020.46228 
A dimensão sensório perceptiva se apresenta como um dos caminhos necessários/fundamentais de contato com o mundo, especialmente nas crianças, porém dificilmente é valorizada pelas professoras e outros adultos como percurso legítimo da produção dos saberes infantis. Uma formação de natureza estética atua no sentido de oportunizar o despertar de uma reflexividade crítica mobilizada pela via sensível, na qual a pessoa é provocada em sua integralidade.

A fim de pensarmos as questões até aqui delineadas - a construção de outra percepção sobre os bebês, como sujeitos de ação na atualidade de seu tempo de vida e as repercussões disso nas práticas pedagógicas das creches - não podemos nos esquivar de refletir simultaneamente sobre a formação docente e sobre as condições nas quais acontecem as interações entre bebês e adultos nas instituições de Educação Infantil (EI).

Para tanto, elaboramos essa escrita em três partes: na primeira, discutiremos o conceito de bebê enquanto sujeito de ação e de direitos; em seguida, trazemos uma concepção de creche como espaço no qual a Educação se concretiza nas práticas sociais que se desdobram, apostando na afirmação e fortalecimento dos vínculos intersubjetivos em prol dos direitos das crianças; traremos também um mapeamento da Rede Municipal do Rio de Janeiro, na qual se insere a creche investigada, a fim de considerar como as condições laborais impactam o trabalho educativo com crianças na medida em que produzem efeitos sobre a qualidade das interações intersubjetivas nas creches. No terceiro momento, discorremos sobre as relações - entre adultos e com os bebês - estabelecidas no contexto da creche em que berçário foi alvo de observações. Por fim, como desdobramento, refletimos sobre a importância de uma formação estética que possa ampliar a atividade cognoscente para além de um empenho intelectual e convocar a multidimensionalidade do humano, apostando na potência das interações sensório-perceptivas com o mundo e com o outro como fios condutores dos processos de aprendizagem - de educadores e educandos.

\section{O SUJEITO BEBÊ}

Nas Unidades Educativas, a cada início de ano letivo acontece o processo de distribuição dos profissionais pelos grupamentos com os quais irão trabalhar. É notável o fato de que há maior disputa pelos grupamentos do Maternal I e II (crianças de 2 a 3 anos e 11 meses) e menor

Revista Interinstitucional Artes de Educar. Rio de Janeiro, V. 6, N.2- pág. 627-652 maio-agosto de 2020: "Bebês e crianças: cultura, linguagem e políticas"

DOI: 10.12957/riae.2020.46228 
interesse pelo Berçário (crianças até 2 anos). Nesse momento do ano são recorrentes algumas falas docentes a respeito dos bebês e do trabalho com bebês: "Eles só sabem fazer xixi, cocô e dormir"; "Eu não tenho perfil para trabalhar com eles"; "Lá é só trabalho braçal"; "Eles não dão retorno dos conteúdos aplicados". Refletindo sobre essas falas, cabe problematizar quais concepções carregam sobre o sujeito bebê e o quanto elas podem impactar as relações estabelecidas com esses sujeitos.

São falas que repercutem o senso comum e revelam uma visão dos bebês como seres passivos, sem conteúdo próprio, cujas ações são apenas fisiológicas e que, por isso, demandam do adulto um empenho unidirecional (sobre o bebê), de viés mecânico, "braçal", aplicacionista. Nessa ótica, os bebês são percebidos como reprodutores da cultura, como "tábulas rasas", e não como atores ativos nas interações com o adulto, o que certamente impacta na realização da Educação Infantil (DAHLBERG; MOSS; PENCE, 2003). Além de não estar em consonância com os documentos normativos, como as Diretrizes Curriculares Nacionais para a Educação Infantil (DCNEI) que, em momento algum, relacionam ações fora do cotidiano como elementos pedagógicos a serem desenvolvidos com os bebês. Essa falta de apropriação dos documentos oficiais não apenas fragiliza a Educação Infantil, como impede um trabalho efetivamente crítico.

Parece existir um desconhecimento da capacidade que os bebês têm de participar ativamente dos processos de socialização próprios, que acontecem a partir das interações com tudo o que fazem - inclusive xixi, cocô, choro - e com todos com quem se relacionam, no tempo presente de sua pouca idade. Os momentos de cuidado são altamente formativos, neles estão em cena aspectos relacionais, afetivos, comunicativos entre adultos e bebês que demandam uma relação essencialmente tônica, sensorial, perceptiva. São, portanto, momentos privilegiados para a construção de vínculos e senso de segurança psicofísica. Mas não se pode descartar a impactante influência do senso comum que, por vezes, confere sentido empobrecido, dicotomizado e funcional aos cuidados, concebidos como algo da ordem de um corpo biofisiológico.

Assim, reconhecer que nos bebês "a fisiologia e a psicologia não se diferenciam, ou apenas começam a fazê-lo" (FALK, 2010, p. 22) é um grande desafio, pois supõe percebê-los de outra maneira: como agentes que ressignificam a cultura, de maneira peculiar e competente no tempo presente. Trata-se, isso sim, de reverter a lógica da incompletude, da fragmentação e considerar o desenvolvimento a partir da lógica da integralidade da pessoa partícipe nesse

Revista Interinstitucional Artes de Educar. Rio de Janeiro, V. 6, N.2- pág. 627-652 maio-agosto de 2020: "Bebês e crianças: cultura, linguagem e políticas" 
percurso e, então, compreender o papel da Educação Infantil e do adulto/docente diante das crianças.

Com isso, entendemos que é preciso ampliar o conceito de bebê considerando-o sujeito de pouquíssima idade que se constitui, conhece e interpreta o mundo a partir das relações que estabelece com o outro - seja a mãe, ou outro adulto de referência -, com o ambiente social, cultural e material que são suas principais fontes de pesquisa e aprendizagem. Uma concepção que permite que reconheçamos neles singularidades e potências, que se voltam ao que são no momento presente. Desse modo, não cabe propagar discursos e práticas que os estigmatizam como não civilizados, como aqueles que não controlam seus esfíncteres, não falam, não andam, não sabem. Essa percepção pela negação, ou por uma “imaginária incompletude” (CHOKLER, 2017, p. 24) contribui apenas para retroceder conquistas de direitos e políticas públicas que, em uma dimensão discursiva, principalmente, vêm edificando a imagem das crianças como cidadãs e sujeitos de direitos.

Ao fazermos uma busca nos principais documentos nacionais que legislam sobre a infância, percebemos que não há consenso e nem definição específica sobre a concepção de bebê. A Lei de Diretrizes e Bases $(\mathrm{LDB}, 1996)^{6}$ não traz nenhuma conceituação acerca do que é ser bebê ou criança. O Estatuto da Criança e do Adolescente (ECA) tampouco menciona o bebê, mas em seu Artigo $2^{\circ}$, estabelece que criança é a "pessoa até doze anos de idade incompletos" (BRASIL, 1990). Já a Lei 13.257 (2016), refere-se à criança de 0 a 6 anos como aqueles pertencentes à primeira infância. As Diretrizes Curriculares Nacionais para a Educação Infantil (DCNEI, 2010), por sua vez, não mencionam o bebê, mas apresentam clara definição de criança como:

Sujeito histórico e de direitos que, nas interações, relações e práticas cotidianas que vivencia, constrói sua identidade pessoal e coletiva, brinca, imagina, fantasia, deseja, aprende, observa, experimenta, narra, questiona e constrói sentidos sobre a natureza e a sociedade, produzindo cultura (BRASIL, 2010, p. 12).

O documento intitulado Referencial Curricular Nacional para a Educação Infantil (RCNEI, 1998) em seu volume I, indica o "não andar" como marco definidor do ser bebê, pois criança é o sujeito que anda. Trata-se de uma definição de bebê pela negatividade do que já se é.

Revista Interinstitucional Artes de Educar. Rio de Janeiro, V. 6, N.2- pág. 627-652 maio-agosto de 2020: "Bebês e crianças: cultura, linguagem e políticas"

DOI: 10.12957/riae.2020.46228 
No volume III, contudo, há pistas de que bebê é o sujeito que tem até 1 ano de idade, a partir de então é considerado criança.

Assim, apenas três documentos pesquisados referem-se ao bebê de forma similar (com pequenas variações), o que aponta uma incipiente tentativa de diferenciar bebês e crianças, a partir de um corte etário. Mais recentemente, a Base Nacional Comum Curricular (BNCC, 2017) traz uma categorização que indica nomenclaturas próprias para cada faixa etária: os bebês são os que têm de 0 a 1 ano e 6 meses; a criança bem pequena, é aquela de 1 ano e 7 meses a 3 anos e 11 meses e a criança pequena, a que tem entre 4 e 5 anos e 11 meses. Essa concepção que adjetiva o substantivo "criança" a depender do grupo etário é corroborada pelos documentos "Subsídios para Diretrizes Curriculares Nacionais Específicas da Educação Básica" (2009a) e "Práticas Cotidianas na Educação Infantil - Bases para a Reflexão sobre as Orientações Curriculares" (2009b), sendo acrescida, neste último, a categoria crianças maiores, que são aquelas de 7 a 12 anos incompletos.

Diante desse quadro, podemos analisar que os documentos que versam sobre as crianças, como sujeitos de direitos e sobre a Educação Infantil como direito das crianças, não explicitam, ainda, definições claras sobre os bebês e suas especificidades. Consideramos, também, que a diferenciação etária é insuficiente para subsidiar, de maneira concreta, uma compreensão acerca das particularidades dos bebês a ponto de orientar as práticas educacionais voltadas para essa população. Além disso, pautar-se em uma progressão etária pode representar mais uma abstração que nos distrai do empenho de construir uma compreensão mais complexa e multidimensional do que significa ser bebê, ser criança e desenvolver-se num enredo social, cultural, histórico onde a educação é compartilhada com a instituição educativa.

Nesse trabalho, procuramos tatear outras pistas que possam colaborar para, gradativamente, tecermos uma compreensão mais abrangente sobre as especificidades dos bebês, considerando que para tanto é imprescindível um olhar interessado e comprometido em conhecêlos a partir de uma apreciação direta, desvelando as potencialidades presentes em seu momento maturativo, por meio das quais interage no mundo. A perspectiva que aqui adotamos procura compreender os bebês

[...] para além de sua condição de sujeito de direito, mas como um sujeito de ação e não só de reação. Como um protagonista ativo, desde o início aberto ao mundo e ao entorno social do qual depende. Sujeito pleno de emoções, de sensações, de afetos, de movimentos, de interesses, de medos, de ansiedades,

Revista Interinstitucional Artes de Educar. Rio de Janeiro, V. 6, N.2-pág. 627-652 maio-agosto de 2020: "Bebês e crianças: cultura, linguagem e politicas" 
capaz de iniciativas, de pensamentos lógicos - com uma lógica própria de seu nível maturativo -, competente para comunicar e para estabelecer vínculos, vividos intensamente em seu corpo e com seu corpo (CHOKLER, 2017, p. 35).

Essa perspectiva traz muitos desafios entre os quais está descobrir, por meio da observação dos bebês em seus enredos socioculturais concretos, o que são. Um novo olhar, sem dúvida, que se volta às impressões sensíveis - vivenciadas no corpo e com o corpo - para então elaborar reflexões acerca das especificidades gerais e individuais desses sujeitos. Entretanto, precisamos também pontuar o fato de que observar é uma ação que demanda tempo, reflexão, interpretação e que nem sempre as condições de trabalho são favoráveis para que isso aconteça.

A seguir, falaremos de tais condições, transitando brevemente por uma contextualização histórica do atendimento institucional à criança no Brasil e mais especificamente sobre o contexto atual da Rede Municipal de Educação do Rio de Janeiro, atentando para o fato de que a construção do direito à Educação Infantil esbarra na necessidade de se pensar as condições do trabalho docente, pois são as docentes, observadoras diárias e possíveis conhecedoras dos bebês pela convivência com eles.

\section{BEBÊ E CRECHE: UMA RELAÇÃO DE DIREITOS EM CONSTRUÇÃO}

Até meados do século XX não havia uma preocupação específica com a Educação voltada às crianças menores e, por conseguinte, tampouco havia exigência de qualificação profissional àqueles que trabalhavam com crianças no contexto institucional. Essa não era uma questão relevante para o Estado até então. Foi a partir das lutas populares, dos movimentos sociais em prol da democratização política no país e principalmente do movimento das mulheres que, em 1988, a Constituição Brasileira pautou a população infantil como prioridade no âmbito das leis e a criança passou a ocupar a categoria de sujeito de direitos e cidadã (LEITE FILHO; NUNES, 2013).

A história do atendimento institucional à criança até então foi marcada por um caráter discriminatório de perspectiva assistencialista, instrumental e reparatória ${ }^{7}$, para as crianças das camadas populares, e preparatória, para as crianças das camadas privilegiadas. Ambas as perspectivas corroboram para a perpetuação do lugar social dessas crianças de acordo com sua origem sociocultural familiar. De um modo ou de outro, as crianças figuravam como um vir a ser (KUHLMANN JR., 2015; KRAMER, 2011), alvos passivos das propostas de socialização

Revista Interinstitucional Artes de Educar. Rio de Janeiro, V. 6, N.2- pág. 627-652 maio-agosto de 2020: "Bebês e crianças: cultura, linguagem e políticas"

DOI: $10.12957 /$ riae.2020.46228 


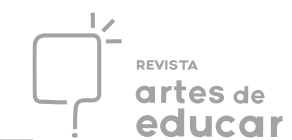

pensadas sob referenciais abstratos, adultocêntricos, principalmente pautados na psicologia do desenvolvimento, fortes orientadores das práticas educacionais a elas destinadas (SOUZA, 1996). O que tem de democrático nessa perspectiva? Precisamos nos perguntar.

A história da formação das professoras de Educação Infantil no Brasil é razoavelmente recente, pois a própria Educação Infantil o é. Sendo assim, pensar esse segmento atualmente requer também (re)conhecer o lugar social dessa etapa educacional especialmente no município do Rio de Janeiro, que é o contexto no qual estamos inseridas. Faremos aqui um breve relato sobre como tem sido a adequação dos quadros profissionais dessa Rede Municipal com vistas a ajustar-se às exigências legais de qualificação mínima para essas professoras, conforme determina a LDB (1996).

Queremos com isso refletir sobre como os contextos concretos das Unidades Educativas acabam por absorver uma série de efeitos das políticas públicas que, ao mesmo tempo em que visam corresponder ao direito da criança à Educação Infantil de qualidade, acabam por gerar uma série de contradições e conflitos no interior das relações de trabalho que dificultam e até precarizam as relações intersubjetivas no contexto dessas instituições.

Essa questão parece indispensável de ser revelada a fim de tratar de maneira coerente e contextualizada a complexidade das configurações dos quadros docentes nas instituições e seus efeitos nas interações profissionais entre adultos e dos adultos com as crianças nas creches. Isso porque a docência é profissão relacional e humana (TARDIF; LESSARD, 2014), o que indica a centralidade do cuidado com as relações com vistas a amalgamar laços de colegialidade, parceria, colaboração no seio do ambiente educacional, de modo a garantir a qualidade do trabalho com as crianças e o aspecto formativo do trabalho pedagógico (OLIVEIRAFORMOSINHO; KISHIMOTO, 2002). Qualidade essa que não prescinde da construção de vínculos interpessoais seguros - entre os profissionais e entre eles e as crianças.

Assim, questionamos as condições que temos construído para cuidar das relações interpessoais e dos vínculos na Educação Infantil. Será que essa é uma pauta considerada pelos gestores e pelas políticas públicas ou mesmo pelos projetos pedagógicos das instituições educacionais?

Falk (2010) salienta que as instituições precisam satisfazer algumas necessidades fundamentais das crianças a fim de garantir seu desenvolvimento global. Entre as quais se encontra a segurança afetiva que consiste no

Revista Interinstitucional Artes de Educar. Rio de Janeiro, V. 6, N.2- pág. 627-652 maio-agosto de 2020: "Bebês e crianças: cultura, linguagem e políticas"

DOI: 10.12957/riae.2020.46228 
estabelecimento e manutenção de relações interpessoais estáveis, contínuas, íntimas e calorosas entre as crianças e número restrito de adultos bem conhecidos e uma relação afetiva privilegiada, autêntica, de caráter específico, profissional, com uma pessoa (cuja forma e conteúdo são particulares dentro do âmbito institucional) (FALK, 2010, p. 26).

Pautando a importância da qualidade das relações interpessoais no âmbito institucional, procuramos aqui traçar um panorama do que está em curso na composição dos quadros profissionais na rede pública de ensino do Rio de Janeiro, em seguida esclarecemos como funciona a Educação Infantil, para então analisar e refletir sobre como as interações interpessoais são também condicionadas pelo contexto do trabalho.

\section{A REDE MUNICIPAL DO RIO DE JANEIRO: COMPLEXO EQUACIONAMENTO ENTRE INTERAÇÕES PROFISSIONAIS E ESPECIFICIDADES INFANTIS}

O município do Rio de Janeiro se constitui como a maior Rede de ensino público da América Latina, estruturada em um nível central que é a Secretaria Municipal de Educação (SME), subdividida em setores denominados: Gerências, que tratam de assuntos específicos (Educação, Educação Infantil, Recursos Humanos, Infraestrutura e Logística, Mídia etc.) e onze Coordenadorias Regionais de Educação (CREs), responsáveis por microrregiões que têm a função de fazer a intermediação entre as propostas da SME e as Unidades Educativas.

A Rede conta com um total de 1.540 escolas, das quais 534 são de Educação Infantil, distribuídas em Creches e Pré-escolas. Estas Unidades abrigam aproximadamente 154.217 crianças, das quais cerca de 60 mil, apenas, estão em Creches. Com relação ao corpo docente, a Rede possui um total geral de 38.198 professores, sendo 5.716 Professores de Educação Infantil (PEI) e 13.501 como Professores II (PII), que têm habilitação para atuar na EI, mas que não necessariamente estão atuando nesse segmento, já que posteriormente foram realizados concursos específicos para Educação Infantil, e com isso, esse profissional foi alocado nas turmas de Ensino Fundamental $\mathrm{I}^{8}$. Há ainda um total de 16.269 funcionários de apoio administrativo, sendo 6.669 Agentes de Educação Infantil (AEI), dos quais 5.155 correspondem a contratos temporários 9 .

No que tange às nomenclaturas e cargos dos profissionais que atuam na Rede em questão, existe o Professor de Educação Infantil (PEI) que prestou concurso específico para atuar nessa

Revista Interinstitucional Artes de Educar. Rio de Janeiro, V. 6, N.2- pág. 627-652 maio-agosto de 2020: "Bebês e crianças: cultura, linguagem e políticas"

DOI: 10.12957/riae.2020.46228 
etapa da Educação Básica, com exigência de qualificação em nível médio, modalidade Normal, cuja carga horária pode ser de 22 horas e trinta minutos, ou de 40 horas semanais, a depender do concurso prestado. Os profissionais que possuem carga horária de 40h e atuam em Creches, ou Espaços de Desenvolvimento Infantil ${ }^{10}$ (SME, 2010a) em horário integral de 9 horas diárias, têm que fazer uma complementação de carga horária, cumprindo uma hora extra por dia para equalizar as 45 horas, que correspondem ao tempo de permanência das crianças nessas Unidades, imprevista pelo estatuto contratual e uma "surpresa" para o contratado, o que faz refletirmos sobre o cuidado com as relações interpessoais na Educação Infantil.

O Professor II (PII) é o profissional com formação mínima exigida de Ensino Médio na modalidade Normal, que ingressou na Rede em concurso prestado antes de 2013, habilitado para atuar da Educação Infantil ao $5^{\circ}$ ano do Ensino Fundamental I. Sua carga horária é de 22 horas e 30 minutos semanais, podendo atuar em escolas de horário parcial, que funcionam em dois turnos (manhã e tarde). Antes de ter sido criado o cargo de Professor de Ensino Fundamental $(P E F)^{11}$, o PII poderia também atuar em escolas de horário integral quando possuísse duas matrículas, quando fizesse Dupla Regência $(D R)^{12}$ ou compartilhando a turma com outro PII.

Hoje, no entanto, com a criação do cargo de $P E F$ (que já prevê a carga horária de 40 horas semanais), os PII foram realocados, em sua maioria, para instituições que não necessariamente atendem à Educação Infantil, mas que funcionam em horário parcial.

Nos detemos aqui em explicar somente os cargos de professores que atuam diretamente com a Educação Infantil. Salientamos que a diversidade de nomenclaturas e especificidades contratuais - tais como carga horária, salário e local de atuação - geram conflitos entre os profissionais que são da mesma categoria e podem, inclusive, atuar numa mesma Unidade Educacional, porém com remuneração distinta. Na nossa experiência, essa situação traz instabilidade nas relações interpessoais, gerando atritos, indisposições e uma tensão que atinge também a interação com as crianças, atuando como elemento de fragmentação nas rotinas, já que é frequente haver uma divisão radical entre ações de "cuidado", realizadas somente pelas Agentes, enquanto as ações "pedagógicas" são organizadas somente pelas Professoras, por exemplo.

O desconhecimento das especificidades da Educação Infantil e a dicotomização entre educar e cuidar, como funções cabíveis a diferentes níveis de qualificação profissional são fortes

Revista Interinstitucional Artes de Educar. Rio de Janeiro, V. 6, N.2-pág. 627-652 maio-agosto de 2020: "Bebês e crianças: cultura, linguagem e políticas" 
vestígios da dificuldade que se tem em considerar a globalidade do desenvolvimento infantil no campo da pedagogia (GUIMARÃES, 2011; KHULMANN JR., 2015).

\section{A EDUCAÇÃO INFANTIL E AS INTERAÇÕES INTERSUBJETIVAS NO CONTEXTO DA REDE MUNICIPAL DO RIO DE JANEIRO}

A Educação Infantil está dividida em duas modalidades: Creche e Pré-escola. A primeira atende crianças de 6 meses a 3 anos e 11 meses e a segunda, de 4 a 5 anos e 11 meses. Tal atendimento é feito em Unidades Educativas que podem se configurar como Creches atendendo exclusivamente crianças até 3 anos e 11 meses de idade -; Espaços de Desenvolvimento Infantil (EDI), que podem atender crianças em faixa etária tanto de creche, quanto de pré-escola ou ambas; Escolas Municipais e Centros Integrados de Educação Pública (CIEP's) - que somente atendem turmas de Pré-escola no seguimento da Educação Infantil, além de atender ao Ensino Fundamental I. Dentro das instituições, a organização para oferta de turmas se dá a partir da demanda da comunidade civil do entorno onde estão inseridas.

A legislação indica que as crianças devem ser agrupadas de acordo com a faixa etária. A creche atende crianças de 0 a 3 anos de idade, da seguinte maneira: de 0 a 11 meses, no Berçário I; de 1 até 1 ano e 11 meses, no Berçário II; de 2 até 2 anos e 11 meses, Maternal I e de 3 até 3 anos e 11 meses, no Maternal II (SME, 2016). Já a Pré-escola atende as crianças de 4 e 5 anos de idade, organizadas em: Pré-escola I - crianças de 4 anos e Pré-escola II - crianças de 5 anos. A Prefeitura do Rio de Janeiro adota uma data limite - 31 de março do ano vigente - para a matrícula em cada uma dessas turmas, sendo assim, as crianças são agrupadas de acordo com sua idade nesta data.

Cada turma tem também um quantitativo máximo de 25 crianças de acordo com definição da Resolução n ${ }^{\circ} 1.427$ da SME - RJ, porém

1.1.5 O acréscimo de $10 \%$ (dez por cento) a este quantitativo ocorrerá quando não houver ainda atendimento à demanda de alunos, com exceção daquelas turmas em que existam alunos com deficiência e transtorno global do desenvolvimento. Nestes casos, deverá ser observada a proporção de adultos por criança (SME, 2016, Anexo III).

Revista Interinstitucional Artes de Educar. Rio de Janeiro, V. 6, N.2- pág. 627-652 maio-agosto de 2020: "Bebês e crianças: cultura, linguagem e políticas"

DOI: 10.12957/riae.2020.46228 
A proporção de adultos para cada criança varia muito e não consta no documento supracitado, apesar da menção feita a ela. No entanto, encontramos informações complementares em outros dois documentos. Apresentamos aqui apenas um deles ${ }^{13}$, o Parecer CNE/CEB n ${ }^{\circ}$ 20/2009, que legisla sobre o sistema público e determina:

O número de crianças por professor deve possibilitar atenção, responsabilidade e interação com as crianças e suas famílias. Levando em consideração as características do espaço físico e das crianças, no caso de agrupamentos com criança de mesma faixa de idade, recomenda-se a proporção de 6 a 8 crianças por professor (no caso de crianças de zero e um ano), 15 crianças por professor (no caso de criança de dois e três anos) e 20 crianças por professor (nos agrupamentos de crianças de quatro e cinco anos) (BRASIL, 2009c, p. 13).

Apesar do que consta no documento citado acima, nem sempre essa é a expressão real do quadro que temos nas instituições de EI do município do Rio de Janeiro, nas quais muitas vezes há uma desproporção entre o número de crianças por adulto. Nesse caso, "em lugar de um ajuste mútuo e pessoal, todas as crianças recebem, mais ou menos, os mesmos cuidados impessoais. [...] o trabalho daquele que se ocupa dela se transforma numa rotina mecânica; sua atitude é impessoal e com frequência indiferente” (FALK, 2010, p. 30).

Sendo assim, se nos propomos a qualificar as relações, pontuamos que o número de crianças sob a responsabilidade de um adulto é elemento fundamental da qualidade da atenção que lhe pode ser dispensada, da possibilidade de enxergar e conferir significado às sutilezas das suas ações, de acompanhar e registrar seus percursos singularmente vividos e de manter uma interação personalizada com cada uma delas, atentando para o aspecto indissociavelmente formativo de tudo o que vivem na instituição educativa.

As conquistas no campo da Educação Infantil a partir da Constituição Federal (1988) e da LDB (1996) aqui enunciadas, se afirmam em um conjunto de leis que as acompanham e/ou as sucedem, para garantir, dentre outros fins, o atendimento profissional devidamente qualificado às especificidades das crianças de 0 a $5 / 6 \operatorname{anos}^{14}$ :

Art. 10. Os profissionais que atuam nos diferentes ambientes de execução das políticas e programas destinados à criança na primeira infância terão acesso garantido e prioritário à qualificação, sob a forma de especialização e atualização, em programas que contemplem, entre outros temas, a especificidade da primeira infância, a estratégia da intersetorialidade na promoção do desenvolvimento integral e a prevenção e a proteção contra toda forma de violência contra a criança (BRASIL, 2016).

Revista Interinstitucional Artes de Educar. Rio de Janeiro, V. 6, N.2- pág. 627-652 maio-agosto de 2020: "Bebês e crianças: cultura, linguagem e políticas"

DOI: 10.12957/riae.2020.46228 


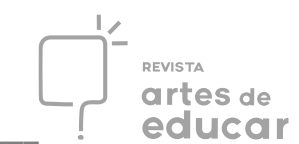

Há outros tantos documentos ${ }^{15}$ (SME, 2010b; 2011; 2013a; 2013b; 2013c), elaborados inicialmente pela Secretaria - e que recentemente contaram com a participação de um grupo de professoras para sua reformulação -, que versam sobre as muitas dimensões que envolvem esse atendimento e vêm norteando as práticas na Educação Infantil da Rede Municipal do Rio de Janeiro, ao menos na perspectiva do que é desejável alcançarem termos de qualidade no trabalho desse segmento. São diversas orientações que, embora necessárias, acabam também por sobrecarregar as professoras com demandas de mais e mais afazeres, complexificando o trabalho e, muitas vezes, deixando-as em uma condição solitária para equacionar tudo que lhes é exigido, sem que as condições para isso sejam garantidas.

Tudo isso revela que há um empenho em qualificar os professores em serviço, contudo, a Rede se forma e transforma a todo momento: profissionais antigos saem e novos chegam; novas categorias e cargos são criados; profissionais são constantemente realocados. Movimentos que falam não somente de renovação, mas principalmente de instabilidade, o que acaba por provocar nós difíceis de serem desembaraçados. Entretanto, "uma das garantias fundamentais de segurança afetiva das crianças educadas em instituições é a continuidade e a qualidade dos relacionamentos entre a criança e o adulto" (FALK, 2010, p. 30), por isso, colocamos em pauta refletir sobre as condições das interações intersubjetivas nas creches públicas da nossa cidade.

Esse esmiuçar das especificidades da composição e organização da Rede Municipal carioca de Educação Infantil se faz necessário para que possamos ter a dimensão do trabalho que vem sendo realizado a fim de garantir melhor atendimento às crianças e, simultaneamente, melhores condições para trabalho docente. O movimento de conquista de direitos é dialético: avança e cria novos desafios, formando uma rede de relações de difícil equacionamento e que, por isso mesmo, precisam ser cuidadas.

Nesse empenho de refletir, novas perguntas aparecem: quem seria responsável por tecer os laços e construir ocasiões de encontros, trocas de ideias, saberes e experiências, principalmente acerca das crianças e seu desenvolvimento nessas equipes que se constituem não por afinidade, mas em ocasião de contratações diversificadas? Como isso pode ser feito?

\section{ESTESIAR O OLHAR: CONSTRUINDO RELAÇÕES EMPÁTICAS POR MEIO DA OBSERVAÇÃO}

Revista Interinstitucional Artes de Educar. Rio de Janeiro, V. 6, N.2- pág. 627-652 maio-agosto de 2020: "Bebês e crianças: cultura, linguagem e políticas"

DOI: 10.12957/riae.2020.46228 
É ainda diante desse contexto que pensamos sobre as concepções de bebês, crianças, Educação Infantil e docência nessa etapa educacional. Temos construído a compreensão de que é imprescindível que as professoras desenvolvam a prática de observar as crianças e suas ações, a fim de criar as condições para que tenham vivências significativas na creche.

Nesse trabalho nos apropriamos de algumas observações realizadas em um berçário frequentado por 25 bebês cujas idades variam de 6 meses a 1 ano e 6 meses. Queremos com isso dar visibilidade tanto aos bebês e seus fazeres, quanto ao fazer pedagógico que ali acontece. Lembrando de que se trata de uma creche pública da Rede Municipal do Rio de Janeiro, que também vem enfrentando o cenário já descrito, e aposta, intencionalmente, em um trabalho de equipe que vem cuidando da qualidade das interações entre os adultos e com as crianças. Há uma pergunta norteadora: como desenvolver e qualificar o trabalho pedagógico com os bebês?

As cenas descritas a seguir foram observadas pela professora da turma do berçário, logo no momento de entrada das crianças na creche. A sala onde os bebês são recebidos está organizada em diversos cantos: no lado direito, brinquedos grandes e macios dispostos em um grande tatame de borracha sobre o chão; no centro da sala temos um pilar de cimento que foi revestido de espuma e transformado em tronco de árvore, compondo um espaço aconchegante com livros e almofadas; no canto esquerdo há instrumentos musicais de plástico e sucatas organizados em caixas baixas, ao alcance dos bebês. Nesse ambiente as crianças podem se posicionar em perspectivas variadas, instigando curiosidades e descobertas, encontros e trocas.

Marina (11 meses) e Emanuel (9 meses) chegam juntos e adentram a sala, sendo acolhidos pelos adultos de referência. Logo os dois se dirigem ao local onde estão dispostos vários livros. Individualmente, pegam alguns deles e os levam à boca. Emanuel se senta em cima de um. Em determinado momento Marina e Emanuel se encontram, se olham e iniciam uma “conversa gestual": pegam um livro, olham juntos, em seguida descartam o livro; começam a sorrir um para o outro, se tocam, pegam as mãos um do outro e continuam nessa interação como se estivessem cantando e batendo palmas.

Revista Interinstitucional Artes de Educar. Rio de Janeiro, V. 6, N.2- pág. 627-652 maio-agosto de 2020: "Bebês e crianças: cultura, linguagem e políticas" 
Figura 1 - Emanuel e Mariana

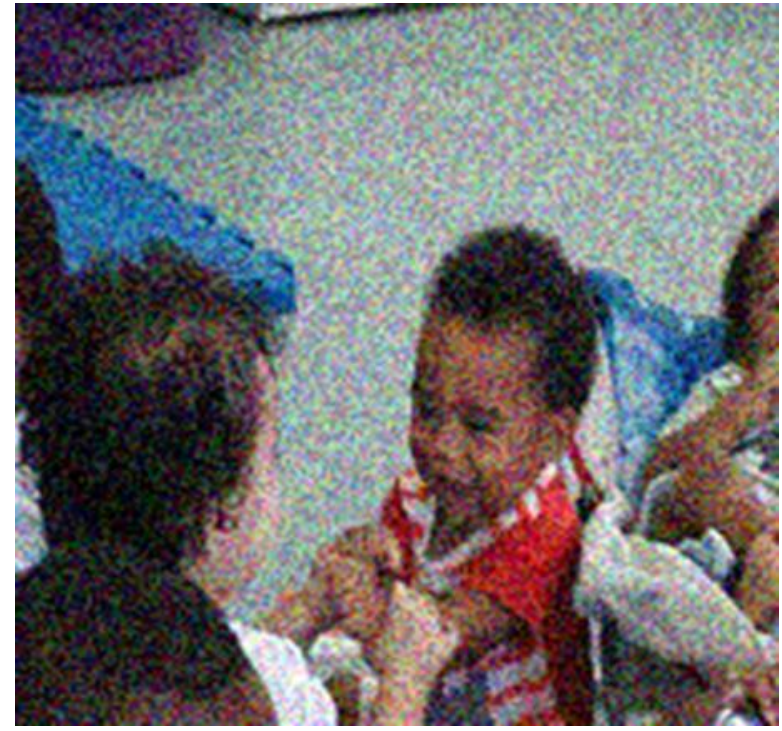

Fonte: Arquivo Pessoal ${ }^{16}$

Figuras 2 e 3 - Emanuel sorrindo e gargalhando para Mariana
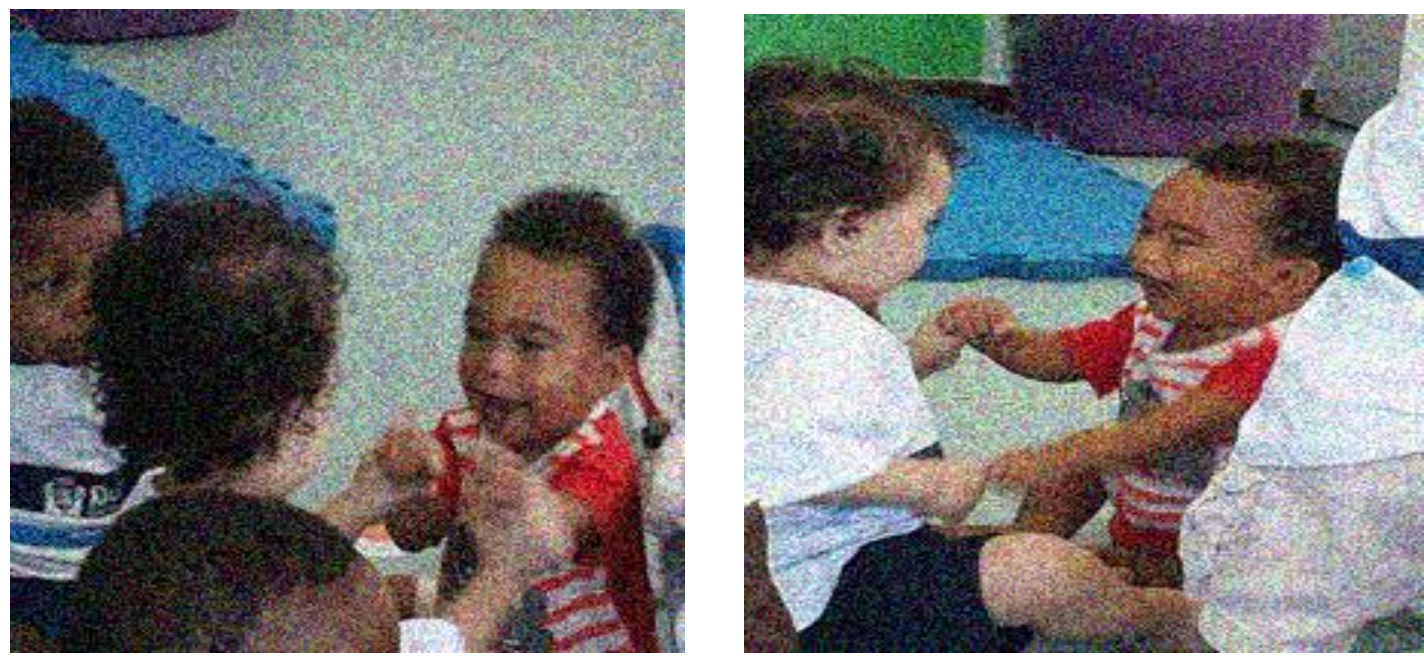

Fonte: Arquivo Pessoal

Nessa cena cotidiana há muito a ser visto e comentado. Os bebês chegaram à sala e puderam se dirigir ao lugar escolhido por eles, de acordo com seus desejos. Além da possibilidade de escolha, as condições ambientais eram adequadas (interessantes e seguras) para se deslocarem livremente.

Revista Interinstitucional Artes de Educar. Rio de Janeiro, V. 6, N.2- pág. 627-652 maio-agosto de 2020: "Bebês e crianças: cultura, linguagem e políticas" 
Observamos que a professora não interferiu diretamente sobre as iniciativas dos bebês, entretanto o espaço fora prévia e intencionalmente organizado a fim de permitir-lhes iniciativas, escolhas, movimentação em condição de segurança. Podemos observar que essa cena revela zelo pelas interações que se desdobraram a partir das iniciativas dos bebês, que são amparadas pelas escolhas das profissionais que preparam o ambiente e, assim, podem manter uma presença não invasiva e observadora diante do que se passa. Havia ali a coexistência respeitosa de iniciativas das crianças e dos adultos, favorecendo a construção de vínculos seguros e afirmativos entre ambos.

O que isso revela a respeito dos valores da escola, dos saberes docentes, ou dos sentidos subjacentes à proposta pedagógica que se materializam nos contornos espaciais e na forma como o espaço pôde ser usado pelos bebês? Entendemos o espaço como "educador" (RINALDI, 2017; EDWARDS; GANDINI; FORMAN, 2016), onde os bebês vivem suas expressões, experiências de encontros, de brincadeira. De acordo com Horn (2003):

[...] o meio assume uma importância significativa, [...] os espaços destinados às crianças pequenas deverão ser desafiadores e acolhedores e, consequentemente, proporcionarão interações entre elas e entre elas e os adultos. Isto se fará na disposição dos móveis e materiais, nas cores, nos odores, nos desafios que, enfim, este meio proporcionará às crianças (HORN, 2003, p. 18).

A atuação indireta do educador fala de alguém que está atento aos interesses dos bebês e lhes prepara um ambiente favorável as suas explorações, no qual é possível que exercitem suas competências psicofísicas, sem grandes sobressaltos (para o educador e para o bebê), tornando assim viável observar o que fazem e admirar sua potência ao, por exemplo, com meses de vida, estabelecer por iniciativa própria, relações com os outros e com as coisas, lançando mão de muitas ações corporais e revelando a riqueza da linguagem não verbal. Observando-os testemunhamos os sujeitos concretos que são.

Outra observação aconteceu no horário do almoço: começamos a organização para o almoço, auxiliando as crianças a se sentarem nas cadeiras. Bryan (7 meses), está no bebê conforto, observando. Continuamos ajudando as crianças a se sentarem. Bryan resmunga. Observamos, mas não o pegamos no colo. Começamos a pegar os primeiros pratos e a servir as crianças. Bryan mais uma vez resmunga e começa a chorar. A professora se abaixa, olha em seus olhos, pega na sua mão, conversa com ele, mas não o leva ao colo. Ao ver a professora pegar

Revista Interinstitucional Artes de Educar. Rio de Janeiro, V. 6, N.2- pág. 627-652 maio-agosto de 2020: "Bebês e crianças: cultura, linguagem e políticas"

DOI: 10.12957/riae.2020.46228 
mais um prato de comida, Bryan, que ainda não recebera seu prato, chora com mais intensidade. A professora vai ao seu encontro e, ao se aproximar, pergunta em tom suave: "Você está com fome?", revelando para ele que entende seu desconforto. Acolhe seu choro, interage olhando nos olhos dele, e seguem conversando, após lhe dar o prato. Nesse momento, ele abre um sorriso e para de chorar. Bryan demonstra que necessita da atenção da professora. Segundo ela, o mesmo acontece quando ele está com sono. São momentos em que ele a requisita e se utiliza do choro para expressar a necessidade de atenção e proximidade.

Observamos nessa cena que Bryan está constantemente atento ao que acontece ao seu redor. Ele demonstra que compreende a rotina e sabe que é hora do almoço. Demonstra também entender o que precisa fazer para ser percebido e atendido em suas necessidades. Cria estratégias para chamar o outro para si: faz ruídos, chora com diferentes intensidades. Esse episódio rotineiro é percebido pela educadora, revelando uma escuta sensível, um olhar atento e não naturalizado para os acontecimentos. Ela para o que está fazendo, se volta para Bryan e lhe oferece um toque significativo e uma fala de interação, que nomeia o está acontecendo e lhe dá uma previsão do que irá acontecer com ele, tranquilizando-o em sua necessidade de ser atendido.

A respeito disso, recorremos a Falk (2010) que ressalta a ideia de continuidade como elemento fundamental para que a criança se sinta segura afetivamente e possa ousar distanciarse, distrair-se, explorar o ambiente, interagir com o outro. A continuidade refere-se não somente à rotina e todos os elementos de repetição e previsibilidade que carregam, como também aos laços afetivos estáveis e calorosos que garantem à criança um enredo de tranquilidade que se torna referência para suas elaborações sobre si, o outro, o ambiente, proporcionando a ela um "sentimento de continuidade de sua existência" (FALK, 2010, p. 26).

De fato, diariamente, conforme vão se familiarizando com os espaços e a organização da rotina, percebemos que estes bebês ousam ocupá-los mais e mais. Observam e se deslocam de maneira engajada; exploram com curiosidade o ambiente que se apresenta cheio de novidades ainda que os elementos ali presentes sejam conhecidos, pois as interações se aprofundam e desdobram, adentrando a condição de intimidade com os próprios gestos, com os objetos, com o outro, que se tornam alvos de uma investigação criteriosa. É nessa imersão no mundo social, coletivo, material que acontecem interações e comunicações, das mais diferentes maneiras, sendo fundamental a presença de um educador que, de fato, esteja imerso num ambiente "onde $o$

Revista Interinstitucional Artes de Educar. Rio de Janeiro, V. 6, N.2- pág. 627-652 maio-agosto de 2020: "Bebês e crianças: cultura, linguagem e políticas"

DOI: 10.12957/riae.2020.46228 
vazio é melhor, pois tem muito espaço para ser preenchido” (BARROS, 1999, p. 26) pela ação da criança.

Estudar, ler livros, participar de palestras, estar em espaços de troca de saberes e experiências nos dá muitas bases para refletir sobre a nossa prática e sobre as potencialidades que os bebês possuem, mas é especialmente complexo e desafiador, quando se está imersa numa turma de berçário, vivenciar e testemunhar as experiências cotidianas com eles. É nesse encontro direto com os bebês que as dimensões discursivas do conhecimento que temos sobre eles interagem e se integram à dimensão sensorial presencialmente vivida. Portanto, é nesse desafio presencial e tônico - de corpo inteiro - que precisamos criar as condições para apreciar os bebês como sujeitos que são e, a partir disso, formular as estratégias concretas de organização do espaço, preparação da rotina e da própria disponibilidade do sujeito educador para favorecer e testemunhar o desenvolvimento infantil acontecendo em percursos singularmente vividos.

Consideramos, nesse sentido, que a formação docente precisa ser pensada e vivida com um olhar mais sensível para as práticas pedagógicas, ou seja, tendo a reflexão sobre a situação concreta do trabalho como mola propulsora de um processo formativo que é permanente e autoformativo. Acreditamos que ao nos conhecermos, sentirmos, experimentarmos, vivenciarmos, teremos mais capacidade de enxergar o cotidiano do trabalho imbricado de "prática-teoria-reflexão-transformação".

A formação reflexiva e ativa precisa incluir as professoras e suas experiências pessoais e profissionais, para que, ao se relacionar com as crianças, tais experiências sejam de fato percebidas e colocadas em movimento de transformação, buscando na própria história concreta e incorporada também do sujeito docente, as condições de disponibilidade e abertura para se relacionar com os bebês de maneira personalizada. Contudo, isso não resulta apenas de um empenho individual: o contexto de trabalho está intimamente implicado com a experiência formativa a partir da prática pedagógica. A depender das condições contextuais, a atividade pedagógica pode ser fator de transformação ou de condicionamentos, de potencialização ou esvaziamento, de colaboração ou isolamento, de sensibilização ou embrutecimento e assim por diante.

Entendemos que personalizar as relações é não ceder às perspectivas tecnicistas do trabalho docente e afirmar sua característica relacional, ética e humana. Por isso, apostamos na formação estética como estratégia de alargamento da sensibilidade docente, acreditando na 
ampliação da percepção para alcançar, ver os modos de ser das crianças e bebês, presenciar sua condição de sujeito e militar por seus direitos. Estesiar é o contrário de anestesiar. É despertar da indiferença, resistir à normatização e esperançar o humano. É deslocar-se do lugar habitual, elarse sensório-perceptivamente ao mundo, ao outro. Percurso necessário para a construção de uma qualidade relacional comprometida, delicada, atenta. Entre adultos e com os bebês.

\section{CONSIDERAÇÕES FINAIS}

Considerando o que foi exposto ao longo deste trabalho, compreendemos que a creche ainda precisa se fortalecer enquanto espaço de Educação dos bebês e romper cada vez mais com a lógica assistencialista e dicotomizadora que ainda hoje confere alguns contornos às formas de educar os bebês. A ruptura com formas condicionadas exige o despertar de uma percepção crítica que, acreditamos, se faz revolvendo os traços da história coletiva introjetados nas nossas próprias histórias de vida e profissão.

A proposta de democratização e universalização da Educação como direito de todos, e principalmente das crianças, nos coloca diante do desafio de acolher toda a diversidade populacional que chega à escola. Contudo, focalizamos aqui as creches e é com a chegada das crianças, sujeitos de direitos que vão materializando novas formas de atuar educacionalmente em contexto de diversidades e singularidades.

A criança que chega à escola tem uma história que precisa ser considerada e acolhida pelos profissionais que lidam com ela. A legitimidade de sua existência é sentida quando sua história, seus gostos, preferências, medos, emoções, sentimentos são cuidados, mas aproximar-se de tudo isso requer um tempo e qualidade relacional, às vezes inviabilizadas pelas condições de trabalho. Há, ainda as interações que se estendem para além do ambiente escolar, com as famílias, também fundamentais para as crianças e seu desenvolvimento, ampliando o sentido de continuidade à relação família-escola.

Compreendemos que a habilidade para enxergar, sentir e acolher os traços personalísticos de cada bebê, desde pequenos, é uma das especificidades do trabalho que realizamos nas instituições educacionais. Mas onde se aprende tal habilidade? Como qualificamos as relações com os bebês, com os pares profissionais da Educação Infantil, com as famílias? Encontramos

Revista Interinstitucional Artes de Educar. Rio de Janeiro, V. 6, N.2- pág. 627-652 maio-agosto de 2020: "Bebês e crianças: cultura, linguagem e políticas"

DOI: 10.12957/riae.2020.46228 
pistas nas próprias interações com esses sujeitos, não é à toa que esse se tornou o eixo do trabalho.

Foi observando, registrando, refletindo conjuntamente sobre o que víamos e interpretávamos a partir das cenas concretas vividas no berçário, entre professoras e bebês, que pudemos começar a pôr em prática nossas concepções, experimentar novos planejamentos, ideias e execução dos projetos, entendendo e testemunhando o bebê como um sujeito ativo, reprodutor e também produtor de cultura e, sobretudo, entendendo que "as educadoras que observam ao mesmo tempo em que atuam podem compartilhar entre elas tudo aquilo que afeta a criança" (FALK, 2010, p. 32) e assim construir entre si uma percepção em continuidade sobre o que testemunham.

Assim, a observação e a intencionalidade nas ações rotineiras, seguida por uma reflexão conjunta sobre o que foi concretamente vivido, foram os meios utilizados para conhecer e se conectar com o bebê, a partir de um olhar minucioso, uma escuta sensível, um toque que dê suporte, um cuidar atencioso e um corpo disponível para desvendar seus gostos, compreender seus choros, gestos, balbucios, perceber suas preferências, nomear suas ações, pois nessa relação a professora aprende, vive experiências e se forma intercambiando sensibilidades, valorizando as interações, "alargando o alcance do olhar e das possibilidades de construção de sentidos diante da vida que pulsa e pede para ser vivida" (OSTETTO, 2011, p. 133), resistindo a naturalizar um cotidiano enrijecido, limitador e cartesiano, em que razão e emoção, cognição e afeto são separados.

A ideia de uma Educação Estética se apresenta como fio contínuo que está presente no binômio educar-cuidar quando se considera a forma como cada coisa é organizada, apresentada, vivida, apreciada. A aprendizagem pela forma, pelo tom de voz, pela materialidade, pela qualidade tônica, pelo olhar, pelo espaço, impressiona de modo direto a dimensão sensível da gente. Aprendemos por meio do que testemunhamos, com os sentidos. O que é especialmente válido quando nos referimos aos bebês e crianças, que recorrem às múltiplas linguagens nas interações com o mundo e com o outro.

Por isso, localizamos o cuidado com as interações como elemento primordial do processo formativo, das professoras no contexto do trabalho, e das crianças no contexto da Educação Infantil: por serem basilares da forma como é possível conhecer e conviver com o outro. Quando este outro é um ser tão misterioso, potente e simultaneamente vulnerável quanto é o bebê, as

Revista Interinstitucional Artes de Educar. Rio de Janeiro, V. 6, N.2-pág. 627-652 maio-agosto de 2020: "Bebês e crianças: cultura, linguagem e políticas" 
interações se tornam ainda mais fundamentais. Contudo, cabe também pensar sobre o cuidado com quem cuida e compreender quais são as condições que favorecem ou inibem uma presença atenta, delicada e dedicada das educadoras com os bebês/educandos e problematizar as condições nas quais trabalham as educadoras de bebês. ${ }^{17}$

\section{REFERÊNCIAS}

BARROS, M. de. Exercícios de ser criança. Rio de Janeiro: Salamandra, 1999.

BRASIL. [Constituição 1988] Constituição da República Federativa do Brasil [recurso eletrônico]. Brasília: Supremo Tribunal Federal, Secretaria de Documentação, 2018.

. Lei no 8.069 de 13 de julho de 1990. Dispõe sobre o Estatuto da Criança e do Adolescente e dá outras providências. Diário Oficial da União, Brasília, 16 jul. 1990.

.Lei $\mathbf{n}^{\circ} 9.394$ de 20 de dezembro de 1996. Estabelece as diretrizes e bases da educação nacional. Diário Oficial da União, Brasília, 23 dez. 1996.

.Ministério da Educação. Referencial Curricular Nacional para a Educação Infantil. Ministério da Educação e do Desporto, Secretaria de Educação Fundamental. — Brasília: MEC/SEF, v. 1, 1998.

.Ministério da Educação. Subsídios para Diretrizes Curriculares Nacionais Específicas da Educação Básica. Brasília: MEC/SEB, 2009a.

.Ministério da Educação. Práticas Cotidianas na Educação Infantil - bases para a reflexão sobre as Orientações Curriculares - Projeto de Cooperação Técnica MEC e UFRGS para Construção de Orientações Curriculares para a Educação Infantil. Brasília: MEC/SEB, 2009b.

.Ministério da Educação. Parecer CNE/CEB n. 20, de 11 de novembro de 2009. Revisa as Diretrizes Curriculares Nacionais para a Educação Infantil. Diário Oficial da República Federativa do Brasil, 9 dez. 2009c, Seção I, p. 14.

.. Ministério da Educação. Secretaria de Educação Básica. Diretrizes Curriculares Nacionais para a Educação Infantil. Brasília: MEC/SEB, 2010.

.. Lei no 13.257 de 8 de março de 2016. Dispõe sobre as políticas públicas para a primeira infância e altera a Lei no 8.069, de 13 de julho de 1990 (Estatuto da Criança e do Adolescente), o Decreto-Lei no 3.689, de 3 de outubro de 1941 (Código de Processo Penal), a Consolidação das Leis do Trabalho (CLT), aprovada pelo Decreto-Lei $n^{\circ} 5.452$, de $1^{\circ}$ de maio de 1943 , a Lei $\mathrm{n}^{\circ}$

Revista Interinstitucional Artes de Educar. Rio de Janeiro, V. 6, N.2- pág. 627-652 maio-agosto de 2020: "Bebês e crianças: cultura, linguagem e políticas" 
11.770, de 9 de setembro de 2008, e a Lei no 12.662, de 5 de junho de 2012. Diário Oficial da União, Brasília, 9 mar. 2016.

.Base Nacional Comum Curricular: Educação Infantil e Ensino Fundamental. Brasília: MEC/Secretaria de Educação Básica, 2017.

CANÁRIO, R. O que é escola? Um olhar sociológico. Porto, Portugal: Porto Editora, 2005.

CANÁRIO, R. A escola tem futuro? Das promessas às incertezas. Porto Alegre: Artmed, 2006.

CHOKLER, M. H. La aventura dialógica de lainfancia. Ciudad Autónoma de Buenos Aires: Cinco, 2017.

CHOKLER, M. H.. Prólogo. In: SZANTO-FEDER, A.. Una mirada adulta sobre e niño em ación: el sentido del movimento de la protoinfancia. Ciudad Autónoma de Buenos Aires: Cinco, 2014.

DAHLBERG, G.; MOSS, P.; PENCE, A.. Construindo a primeira infância: o que achamos que isto seja. In: Qualidade na educação da primeira infância: perspectivas pós modernas. Porto Alegre: Artmed, 2003, p. 63-85.

EDWARDS, C.; GANDINI, L.; FORMAN, G. (Orgs.). As cem linguagens da criança: a experiência de ReggioEmilia em transformação. Porto Alegre: Penso, 2016.

FALK, J. A estabilidade por meio da continuidade e qualidade dos cuidados e das relações. In: (Org.). Abordagem Pikler: educação infantil. São Paulo: Ominisciência, 2016, 25-39.

GUIMARÃES, D. Relações entre bebês e adultos na creche: o cuidado como ética. São Paulo: Cortez, 2011.

HERMANN, N.. Ética e estética: a relação quase esquecida. Porto Alegre: EDIPUCRS, 2005. (Coleção Filosofia)

HORN, M. da G. S.. O papel do espaço na formação e transformação da ação pedagógica do educador infantil. 2003. 151 f. Tese (Doutorado em Educação) - Faculdade de Educação, Universidade Federal do Rio Grande do Sul, Porto Alegre.

KRAMER, S.. A política do pré-escolar no Brasil: a arte do disfarce. São Paulo: Cortez, 2011.

KUHLMANN JUNIOR, M.. Infância e Educação Infantil: uma abordagem histórica. Porto Alegre: Mediação, 2015.

LEITE FILHO A.; NUNES, M. F.. Direitos da criança à educação infantil: reflexões sobre a história e a política. In: KRAMER, S.; NUNES, M. ; CARVALHO, M. C. (Orgs.). Educação Infantil: Formação e responsabilidade. Campinas, SP: Papirus, 2013, p. 67-87.

Revista Interinstitucional Artes de Educar. Rio de Janeiro, V. 6, N.2- pág. 627-652 maio-agosto de 2020: "Bebês e crianças: cultura, linguagem e políticas" 
OLIVEIRA-FORMOSINHO, J.; KISHIMOTTO, T. M. K.. Formação em Contexto: uma estratégia de integração. São Paulo: Thomson Pioneira, 2002.

OSTETTO, L. E. Educação Infantil e Arte: sentidos e práticas possíveis. Acervo digital UNESP, mar. 2011. Disponível em:

https://acervodigital.unesp.br/bitstream/123456789/320/1/01d14t01.pdf

SECRETARIA MUNICIPAL DE EDUCAÇÃO. Espaço de Desenvolvimento Infantil (EDI): modelo conceitual e estrutura. Rio de Janeiro, fev. 2010a.

. Orientações para profissionais da Educação Infantil. Rio de Janeiro, jul. 2010b. $\overrightarrow{2011 .}$

,Planejamento na Educação Infantil. Cadernos Pedagógicos, vol. I, Rio de Janeiro, fev.

A avaliação na Educação Infantil. Rio de Janeiro, jul. 2013a.

Orientações para a organização da sala na Educação Infantil: ambiente para a criança criar, mexer, interagir e aprender. Rio de Janeiro, mar. $2013 \mathrm{~b}$.

,. Orientações ao Professor de Pré-escola I e II. Rio de Janeiro, $1^{\circ}$ semestre de 2013 c.

Resolução $n^{\circ}$ 1427, de 24 de outubro de 2016. Dispõe sobre a estrutura de atendimento, organização de turmas, horário de funcionamento e Matriz Curricular das Unidades Escolares da Rede Pública de Ensino da Cidade do Rio de Janeiro. Diário Oficial do Município, Rio de Janeiro, 26 out. 2016.

RINALDI, C.. Diálogos com Reggio Emilia: escutar, investigar e aprender. Rio de Janeiro/São Paulo: Paz e Terra, 2017.

SOUZA, S. J.. Re-significando a psicologia do desenvolvimento: uma contribuição crítica à pesquisa da infância. In: KRAMER, S.; LEITE, M. I. (Orgs.). Infância: fios e desafios da pesquisa. Campinas, SP: Papirus, 1996, p.39-56.

SZANTO-FEDER, A.; TARDOS, A. O que é autonomia na primeira infância? In: FALK, J. (Org.). Educar os três primeiros anos: a experiência de Lóczy. Araraquara, SP:

Junqueira\&Marin, 2011, p. 33-46.

TARDIF, M.. Saberes docentes e formação profissional. 17.ed. Petrópolis, RJ: Vozes, 2014.

TARDIF, M.; LESSARD, C.. O trabalho docente: elementos para uma teoria da docência como profissão de interações humanas. Rio de Janeiro: Vozes, 2014.

Revista Interinstitucional Artes de Educar. Rio de Janeiro, V. 6, N.2- pág. 627-652 maio-agosto de 2020: "Bebês e crianças: cultura, linguagem e políticas"

DOI: 10.12957/riae.2020.46228 


\begin{abstract}
i Mestranda em Educação pela Universidade Federal do Estado do Rio de Janeiro (UNIRIO). Graduada em Pedagogia pela Universidade do Estado do Rio de Janeiro (UERJ). Especialista em Docência na Educação Infantil (UFRJ). Pesquisadora, desde 2013, do grupo FRESTAS (Formação e Resignificação do Educador: Saberes, Troca, Arte e Sentidos), pertencente ao Núcleo Infância, Natureza e Arte (NINA), vinculado à UNIRIO. Professora da Educação Básica do Município do Rio de Janeiro (Educação Infantil). E-mail: laneoliveirasilva@ @hotmail.com Rio de Janeiro/RJ, Brasil. ORCID: https://orcid.org/0000-0002-6422-412
\end{abstract}

ii Mestre em Educação pela PUC-Rio (2018). Especializou-se em Educação Infantil pela PUC-RJ (2013). Tem licenciatura em Dança Contemporânea pela Faculdade Angel Vianna - RJ (2009). Formou-se professora da Técnica Alexander, no Alexander Technique Studio - Londres (2002); essa prática constitui referência de suas reflexões e ações sobre as interações corpo, educação e espaços educativos. Atua como professora de linguagem corporal na Educação Infantil desde 2010. É pesquisadora do grupo de pesquisa FRESTAS, vinculado à UNIRIO, desde 2016. Email: lagelivia@gmail.com Rio de Janeiro/RJ, Brasil. ORCID: https://orcid.org/0000-0002-8021-0555

iii Mestranda em Educação pela Universidade Federal do Estado do Rio de Janeiro (UNIRIO). Graduada em Pedagogia pela Universidade do Estado do Rio de Janeiro (UERJ). Professora da Prefeitura do Rio de Janeiro há 17 anos, ocupando atualmente a função de Diretora Adjunta de um Centro Integrado de Educação Pública (CIEP). Pesquisadora do Grupo FRESTAS (Formação e Ressignificação do Educador: Saberes, Arte, Troca, Sentidos) vinculado ao NINA (Núcleo Infância, Natureza e Arte) na Universidade Federal do Estado do Rio de Janeiro (UNIRIO). E-mail: michaduda@yahoo.com.br Rio de Janeiro/RJ, Brasil. ORCID: https://orcid.org/0000-00028314-1903

${ }^{4}$ Levando-se em consideração a predominância majoritária das mulheres na função docente, especialmente na Educação Infantil, por conta de uma realidade institucional historicamente constituída, optamos por, ao nos referirmos à figura docente, utilizar a palavra "professora" no feminino.

${ }^{5}$ Transcrevemos aqui, literalmente, a frase do autor em questão. Entretanto, não estamos tratando crianças como alunos, mas pensar na homologia entre as experiências dos professores e das crianças no âmbito de atuação institucional escolar.

${ }^{6}$ Somente em 1996, com a LDB, e em correspondência ao direito das crianças, a Educação Infantil passou a integrar a Educação Básica brasileira, tornando-se responsabilidade compartilhada entre família e Estado. Sua finalidade é promover desenvolvimento integral da criança - nos aspectos físico, psicológico, intelectual e social -, e o atendimento se dá em Creches, para crianças até 3 anos e Pré-escolas, para crianças de 4 a 6 anos de idade (Artigos 29 e 30 respectivamente).

${ }^{7}$ Nos referimos à ideia de "privação cultural" formulada segundo referenciais normativos sobre a existência de uma suposta criança normal, que se constitui em referência às crianças das camadas sociais mais altas. Os desviantes de tal normalidade seriam vítimas das supostas carências socioculturais familiares, que poderiam ser corrigidas no percurso educacional. Essa visão desqualifica a diversidade das experiências culturais e atua para ajustar todas as crianças a um padrão predeterminado e genérico, por isso abstrato. Sonia Kramer versa sobre essa concepção no livro A política do pré-escolar no Brasil: a arte do disfarce (2011).

${ }^{8}$ O PII é o profissional habilitado para atender turmas da Educação Infantil ao Ensino Fundamental I - que vai do $1^{\circ}$ ao $5^{\circ}$ ano -, por conta dessa mobilidade, aqueles que eram PII e estavam em turmas de Educação Infantil, foram sendo substituídos pelos Professores de Educação Infantil (PEIs), cujo concurso prestado permitia atuar apenas na Educação Infantil. No entanto, isso não foi efetivado em toda a Rede, visto o tamanho e a falta de profissionais em todas as CREs.

${ }^{9}$ Dados disponíveis na página da Secretaria Municipal de Educação (SME), referentes a outubro de 2019: http://www.rio.ri.gov.br/web/sme/educacao-em-numeros

${ }^{10}$ Ver o documento "Espaço de Desenvolvimento Infantil (EDI): modelo conceitual e estrutura" (SME, 2010) para informação mais completa.

Revista Interinstitucional Artes de Educar. Rio de Janeiro, V. 6, N.2-pág. 627-652 maio-agosto de 2020: "Bebês e crianças: cultura, linguagem e políticas"

DOI: 10.12957/riae.2020.46228 
${ }^{11}$ O cargo de PEF foi criado em 1 de outubro de 2013, segundo a Lei no 5623 , que dispõe sobre o plano de cargos, carreiras e remuneração dos funcionários da Secretaria Municipal de Educação e dá outras providências. Disponível em: leismunicipais.com.br/a/rj/r/rio-de-janeiro/lei-ordinaria/2013/562/5623/lei-ordinaria-n-5623-2013-dispoe-sobreo-plano-de-cargos-carreiras-e-remuneracao-dos-funcionarios-da-secretaria-municipal-de-educacao-e-da-outrasprovidencias.

${ }^{12}$ Devido à falta de profissionais para suprir o atendimento a todas as turmas das Unidades Escolares, foi criada a dupla jornada de atendimento. No entanto, como não são efetivamente concursados e não podem assumir duas matrículas, os profissionais que fazem Dupla Regência, recebem um salário de acordo com o vencimento do seu cargo, tendo acrescido a ele o transporte, mas sem descontos previdenciários. Porém, tal recebimento acontece apenas em meses de efetivo exercício, não conta para aposentadoria e pode ser interrompido a qualquer momento, já que tem efeito de hora extra.

${ }^{13}$ O segundo é da Deliberação E/CME n 30/2019 que, apesar de fixar norma, com a participação de funcionários das Gerências de Educação e Educação Infantil da SME.

${ }^{14}$ Existe aqui uma variação acerca da idade das crianças, pois em alguns documentos consta 5 anos (LDB, Constituição, DCNEI), em outros 6 anos (BNCC). Isso se deve ao fato de as crianças completarem 6 anos ao longo do ano em que estão na Educação Infantil.

15 Tais como: “Orientações para a organização da sala na Educação Infantil: ambiente para a criança criar, mexer, interagir e aprender" (SME, 2013) que trata dos espaços físicos; "A avaliação na Educação Infantil” (SME, 2013) que discute as peculiaridades da avaliação nessa etapa educacional; "Planejamento na Educação Infantil: cadernos pedagógicos" (SME, 2011) que discorre sobre a temática do planejamento, do registro e das rotinas; "Orientações para profissionais da Educação Infantil” (SME, 2010) que abordam questões relativas ao cuidado com o ambiente, com a criança e com a comunidade e "Orientações ao Professor de Pré-escola I e II" (SME, 2013) voltado para a Pré-escola, apresenta o trabalho com as apostilas e sugere os conhecimentos a serem adquiridos nela.

${ }^{16}$ Apesar de termos autorização dos responsáveis de ambas as crianças para uso da imagem, entendemos que são crianças bem pequenas e como tais, não têm como escolher se querem ou não esse tipo de exposição. Por isso, buscando uma relação mais ética, optamos por usar um efeito na foto para descaracterizá-la, sem comprometer a observação.

Revista Interinstitucional Artes de Educar. Rio de Janeiro, V. 6, N.2- pág. 627-652 maio-agosto de 2020: "Bebês e crianças: cultura, linguagem e políticas" 